\title{
The effect of Bond number on pool boiling for mini-fin surfaces and different working fluids
}

\author{
Ewelina Strąk $\mathrm{k}^{1, \mathrm{a}}$, Robert Pastuszko ${ }^{1, \mathrm{~b}}$ \\ ${ }^{1}$ Kielce University of Technology, Al. 1000-lecia P.P. 7, 25-314 Kielce, Poland
}

\begin{abstract}
Experimental nucleate pool boiling data were collected for structures in the form of extended surfaces sintered with perforated foil. The article describes experimental investigations for two kinds of surfaces: smooth and mini-fins with sintered perforated foil (MFP). The MFP surfaces were manufactured out of perforated copper foil (pore diameters: $0.05-0.3 \mathrm{~mm}$ ) sintered with the mini-fins, uniformly spaced on the base surface.

The experiments were carried out at atmospheric pressure for four kinds of the fluids: water, ethanol, FC-72 and Novec 649. The results for these working fluids were compared in terms of the Bond number and other dimensionless parameters. For all working fluids, the heat transfer coefficients obtained for the MFP surfaces were from 2 to 5 times higher than those for the smooth surface.

Using a regression analysis with reference to selected physical properties and several characteristic dimensions, it was possible to develop a correlation for the Nusselt number.
\end{abstract}

\section{Introduction}

Pool boiling heat transfer has generally been associated with a combination of microconvection, vapor-liquid exchange, evaporation, latent heat and transient conduction. Vapor bubble dynamics, that is, bubble nucleation, growth, and departure as well as rewetting of the heater surface is the main pool boiling heat transfer mechanism.

This article describes the influence of the similarity numbers on pool boiling from mini-fin surfaces with water, ethanol, FC-72 and Novec 649 as working fluids.

The correlation formulas can also be found in the literature below.

In [1], the correlation is similar to that proposed by Rohsenow. The experimental data have been obtained for seven kinds of fluids (water, ethanol, $\mathrm{CCl}_{4}$, acetone, n-hexane, R113, R141b) and for the plain surfaces without capillary structures under variable pressure. These surfaces include ordinary metal, metal with a coating and nonmetals of high thermal conductivity.

The correlation in [2] has been obtained for five fluids (R-113, n-pentane, ethanol, water and R-11) boiling on the plain, low finned surfaces and on the Gewa-T surfaces at atmospheric pressure.

Moita et al. in [3] reports the results of a detailed heat transfer and bubble dynamics analysis for pool

\footnotetext{
a Corresponding author: enadstawna@tu.kielce.pl
}

boiling with three fluids (water, ethanol and HFE 7000) boiling on smooth and micro-structured surfaces. The bubble departure diameter is described as a function of the Jakob number.

E. van Rooyen and J.R. Thome [4] studied TurboB5 and Gewa-B5 enhanced surfaces. The experiment were carried out with used refrigerants R-134a, R-236fa and R-1234ze(E). Their correlation was based on a boiling heat transfer mechanism in the near-wall region.

The authors of this paper presented the effect of Bond number on boiling heat transfer coefficient and proposed their own correlation equation for the Nusselt number related to five dimensionless numbers.

\section{Experimental research}

\subsection{Investigated surfaces}

\subsubsection{Mini-fins with porous structure (MFP) surfaces}

The test surfaces, presented in figure 1, were fabricated out of copper to dimensions $26.5 \times 26.5 \mathrm{~mm}^{2}$. The minifins tips were added to the smooth surface and the perforated copper foil was sintered to the mini-fin tips. 
In MFP surfaces the tunnel width in each direction was constant.

The tests were carried out for different diameters of pores in the copper foil $\left(d_{p}=0.05,0.1,0.2\right.$ and $\left.0.3 \mathrm{~mm}\right)$. The parameters of the investigated surfaces and their designations are shown in table 1 . In the figure $1, p_{p 1}$ means the pitch thickness in one direction in the copper foil and $p_{p 2}$ means the pitch thickness in the second direction. In table $1, \delta$ means the mini-fin thickness, $p_{\text {tun }}$ - is the tunnel pitch, $w_{t u n}$ - is the tunnel width, $s-$ is the distance between the mini-fins and $h-$ is the mini-fin height.

Table 1. Parameters of surfaces tested.

\begin{tabular}{|c|c|c|c|c|c|c|c|}
\hline \multirow{2}{*}{ Surface } & $\boldsymbol{\delta}$ & $\boldsymbol{p}_{\text {tun }}$ & $\boldsymbol{s}$ & $\boldsymbol{w}_{\text {tun }}$ & $\boldsymbol{h}$ & $\boldsymbol{d}_{\boldsymbol{p}}$ & $\boldsymbol{p}_{\boldsymbol{p} 1} / \boldsymbol{p}_{\boldsymbol{p} 2}$ \\
\cline { 2 - 9 } & {$[\mathrm{mm}]$} & {$[\mathrm{mm}]$} & {$[\mathrm{mm}]$} & {$[\mathrm{mm}]$} & {$[\mathrm{mm}]$} & {$[\mathrm{mm}]$} & {$[\mathrm{mm}]$} \\
\hline MFP-1.0-0.6-0.05 & 2.0 & 2.0 & 1.4 & 0.6 & 1.0 & 0.05 & $0.1 / 0.4$ \\
\hline MFP-1.0-0.6-0.1 & 2.0 & 2.0 & 1.4 & 0.6 & 1.0 & 0.1 & $0.2 / 0.4$ \\
\hline MFP-1.0-0.6-0.2 & 2.0 & 2.0 & 1.4 & 0.6 & 1.0 & 0.2 & $0.4 / 0.4$ \\
\hline MFP-1.0-0.6-0.3 & 2.0 & 2.0 & 1.4 & 0.6 & 1.0 & 0.3 & $0.6 / 0.4$ \\
\hline Smooth & - & - & - & - & - & - & - \\
\hline
\end{tabular}
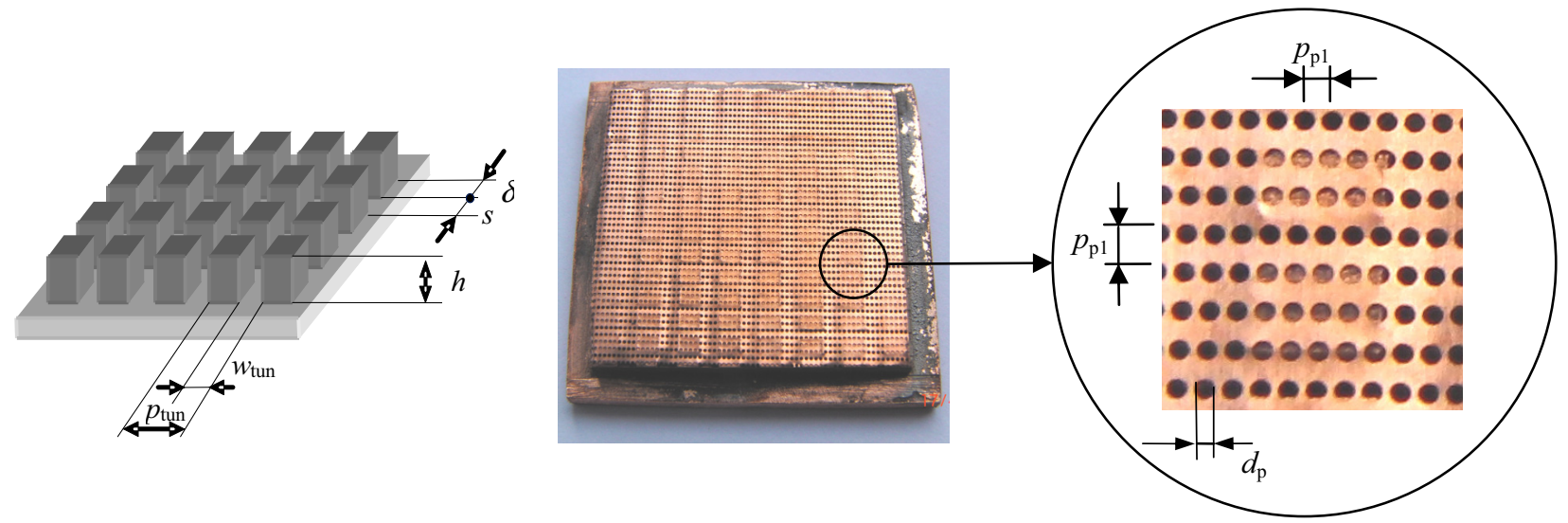

Figure 1. Dimension symbols and a photograph of mini-fin surface sintered with perforated foil (MFP)[5].

\subsection{Experimental set-up}

The measurement system, presented in figure 2, was designed for determining boiling curves and heat transfer coefficients.

The main device in the measurement system is the basic module supplied with alternating current by an autotransformer. The input power is measured by a wattmeter. Signals from thermocouples are collected by data logger and transferred to the PC.

The main module is instrumented with 7 thermocouples (figure 2): 2 for measuring the saturation temperature (items I, II), 2 for measuring the temperature of the base of the sample (items III, IV), and 3 for determining the heat flux (items V, VI, VII).

Selected thermodynamic properties of four working fluids used in the experiments, at the saturation temperature, are summarized in table 2 .

From the experimental data, the heat flux, temperature superheating and heat transfer coefficient were calculated. The obtained results were compared with the Bond number and geometric parameters of surfaces after appropriate transformations.
Table 2. Thermodynamic parameters of saturated fluids [5, 6].

\begin{tabular}{|c|c|c|c|c|}
\hline $\begin{array}{c}\text { Parameters } \\
\text { at } \boldsymbol{p}=\mathbf{1 0 1 . 3} \\
\mathbf{k P a}\end{array}$ & Water & Ethanol & FC-72 & $\begin{array}{c}\text { Novec } \\
\mathbf{6 4 9}\end{array}$ \\
\hline$T_{\text {sat }}{ }^{0} \mathrm{C}$ & 100 & 78.3 & 56.4 & 49.0 \\
\hline$\rho_{l}, \mathrm{~kg} / \mathrm{m}^{3}$ & 959 & 757 & 1602 & 1610 \\
\hline$\rho_{v}, \mathrm{~kg} / \mathrm{m}^{3}$ & 0.597 & 1.43 & 13.24 & 4.33 \\
\hline$\lambda_{l}, \mathrm{~W} / \mathrm{mK}$ & 0.68 & 0.17 & 0.054 & 0.059 \\
\hline$\sigma_{l,} \mathrm{~N} / \mathrm{m}$ & 0.0589 & 0.0177 & 0.0081 & 0.0108 \\
\hline$c_{l}, \mathrm{~J} / \mathrm{kgK}$ & 4220 & 723 & 1103 & 1103 \\
\hline$h_{l,}, \mathrm{~kJ} / \mathrm{kg}$ & 2257 & 963 & 88 & 88 \\
\hline$\mu_{l}, \mathrm{~Pa} \cdot \mathrm{s}$ & 0.00028 & 0.00044 & 0.00043 & 0.00043 \\
\hline$L, \mathrm{~mm}$ & 2.5 & 1.55 & 0.72 & 0.83 \\
\hline
\end{tabular}

where:

$L \quad$ - capillary length (eq. 2), $\mathrm{mm}$

$T_{\text {sat }}$ - saturation temperature, ${ }^{\circ} \mathrm{C}$ 
$\rho_{l} \quad$ - saturated liquid density, $\mathrm{kg} / \mathrm{m}^{3}$

$\rho_{v}$ - saturated vapor density, $\mathrm{kg} / \mathrm{m}^{3}$

$\sigma_{l}-$ liquid surface tension, $\mathrm{N} / \mathrm{m}$

$\lambda_{l}, \quad$ - liquid thermal conductivity, $\mathrm{W} / \mathrm{m} \cdot \mathrm{K}$ $c_{l} \quad-$ specific heat, $\mathrm{J} / \mathrm{kg} \cdot \mathrm{K}$

$h_{l v}$ - latent heat, $\mathrm{J} / \mathrm{kg}$

$\mu_{l}$ - dynamic viscosity, Pa.s.

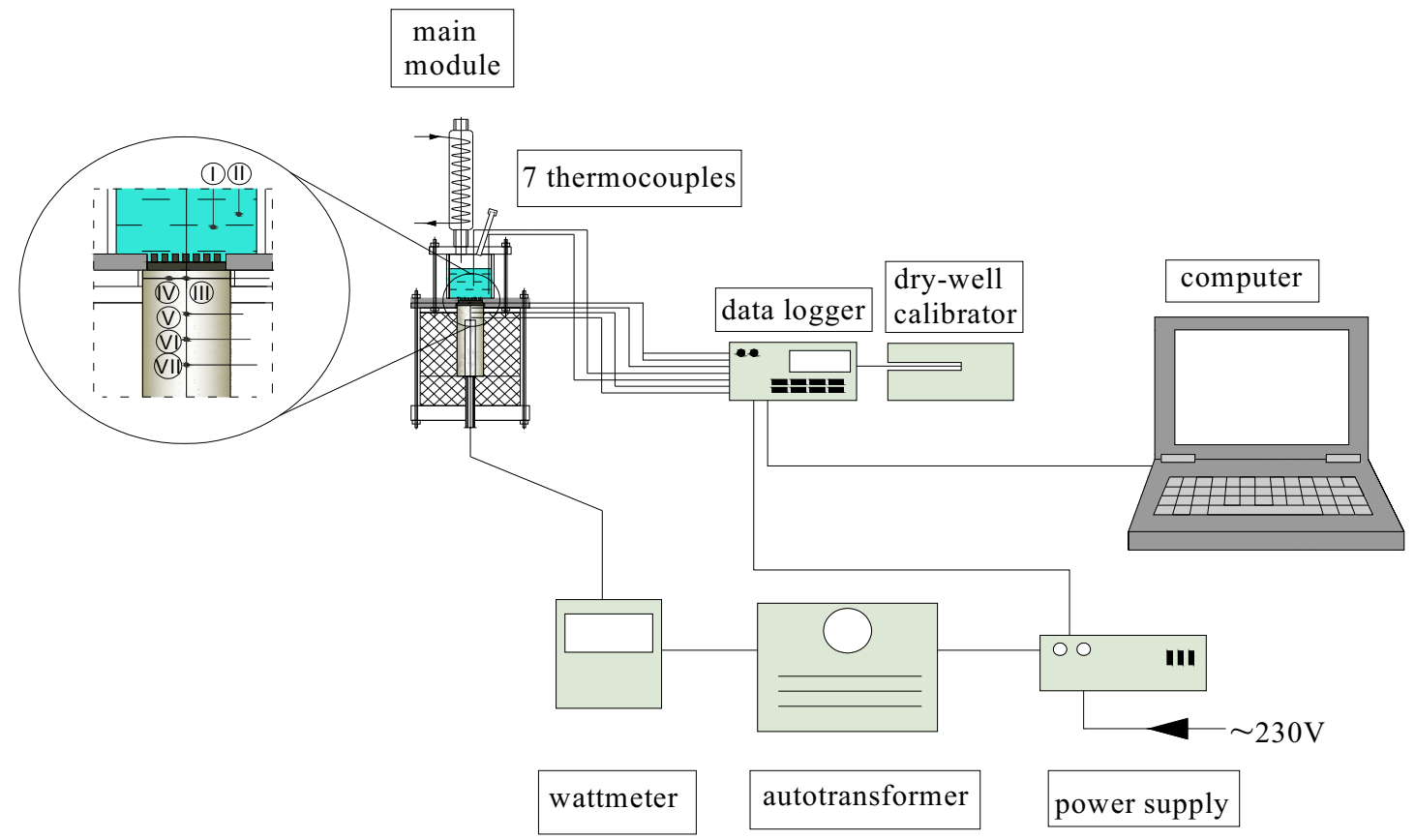

Figure 2. Measurement system.

\section{Results}

\subsection{Bond number}

The Bond number is the ratio of characteristic dimension (pore diameter, $d_{\mathrm{p}}$ ) to capillary length. For MFP surfaces this similarity number was calculated from the following formula

$$
B o_{d}=\left(\frac{d_{p}}{L}\right)^{2}
$$

The capillary length which characterizes the potential for bubble departure and coalescence is defined by the equation

$$
L=\sqrt{\frac{\sigma_{l}}{g\left(\rho_{l}-\rho_{v}\right)}}
$$

where

$g$ - gravitational acceleration, $\mathrm{m} / \mathrm{s}^{2}$.

\subsection{Generalized results}

The experimental data helped to generalize the results in the form of the relationship between the MFP surface heat transfer coefficient/smooth flat surface coefficient ratio on the Bond number and varying geometric parameters.

For mini-fin surfaces, the proposed relationship is as follows $[6,7]$

$$
\frac{\alpha}{\alpha_{s}}=f\left(B o_{d}{ }^{0,5} \frac{w_{\text {tun }}}{h}\right)=f\left(\frac{d_{p}}{L} \frac{w_{\text {tun }}}{h}\right)
$$

where

$\alpha$ - heat transfer coefficient for the MFP surfaces, $\mathrm{W} / \mathrm{m}^{2} \mathrm{~K}$

$\alpha_{s}-$ heat transfer coefficient for smooth surfaces, $\mathrm{W} / \mathrm{m}^{2} \mathrm{~K}$

$d_{p}-$ pore diameter, $\mathrm{m}$.

The calculation results for four working fluids are presented in figure 3. Boiling heat transfer coefficients for the smooth surfaces were determined on the basis of the power-law data approximation:

- for ethanol: $\quad \alpha_{s}=0.18 \cdot q^{0.68}$

- for water: $\quad \alpha_{s}=0.39 \cdot q^{0.70}$

- for FC-72: $\quad \alpha_{s}=0.11 \cdot q^{0.72}$

- for Novec 649: $\alpha_{s}=0.20 \cdot q^{0.59}$

where:

$q$ - heat flux, $\mathrm{W} / \mathrm{m}^{2}$. 


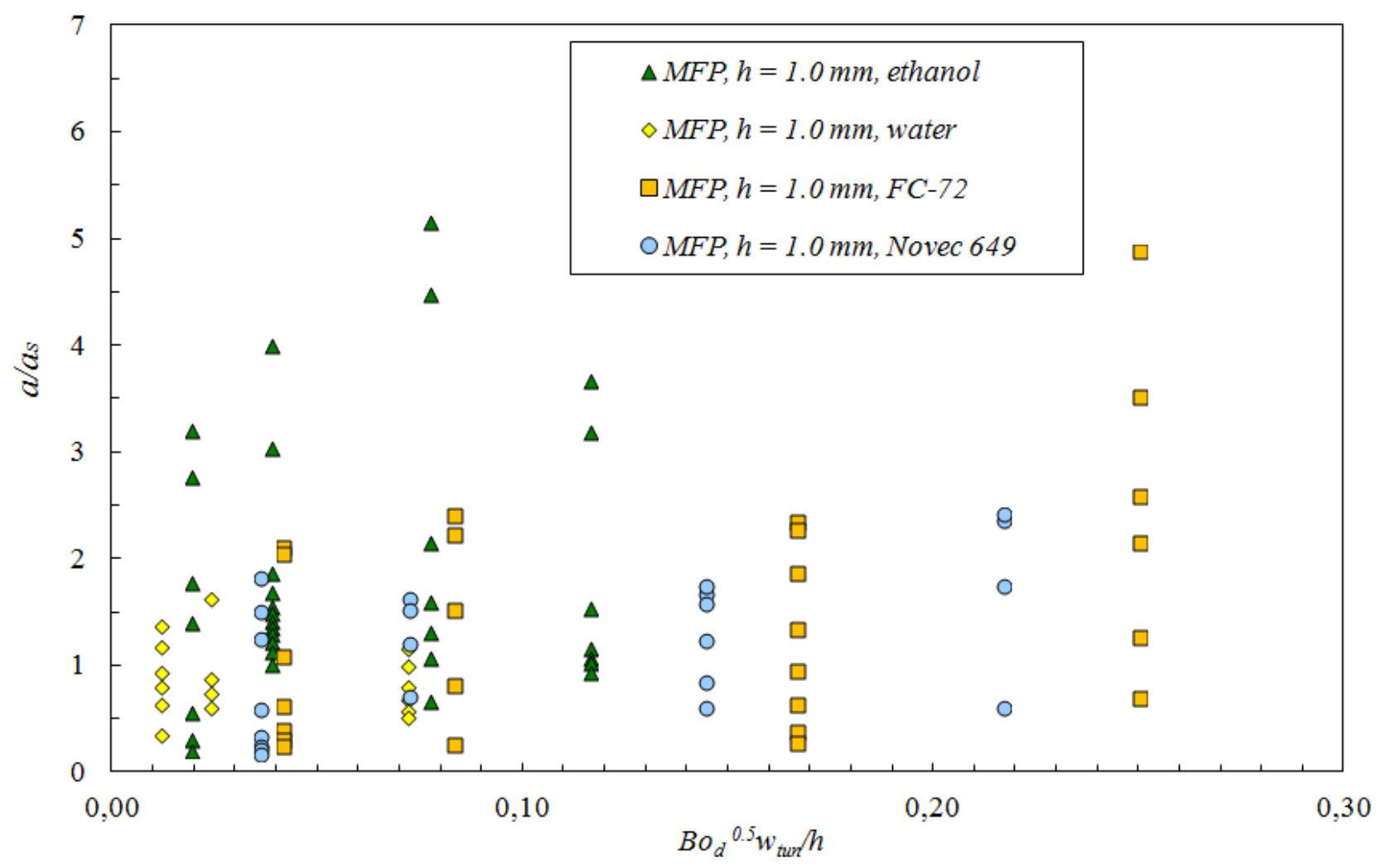

Figure 3. Generalized results for the MFP surface.

From the graph it can be concluded that the highest heat transfer coefficients for the mini-fin surfaces are obtained for the following ranges of similarity numbers:

- for ethanol

$0.04<B o_{d}{ }^{0.5} \frac{w_{\text {tun }}}{h}<0.08$

- for water

$0.013<B o_{d}{ }^{0.5} \frac{w_{\text {tun }}}{h}<0.025$

- for FC-72

$B o_{d}^{0.5} \frac{w_{\text {tun }}}{h} \approx 0.25$

- for Novec 649

$$
\operatorname{Bo}_{d}{ }^{0.5} \frac{w_{\text {tun }}}{h} \approx 0.22
$$

The highest ratio between the MFP surface heat transfer coefficients and the smooth flat surface coefficients was observed for the boiling of ethanol and FC-72.

\subsection{Correlation}

A correlation was proposed in the form of a relationship between the Nusselt number and five similarity numbers. The Reynolds and Bond numbers were associated with the cooper foil pore diameter. The dimensionless number
$K_{\mathrm{w}}$ expressed the relationships between the tunnel width and the copper foil pore diameter. Number $K_{\lambda}$ shows the ratio of the mini-fin material (copper) thermal conductivity $\lambda_{C u}$ to the thermal conductivity of the boiling liquid $\lambda_{l}$.

The following correlation was proposed

$$
N u_{\text {theor }}=0.007 \operatorname{Re}^{0.025} \operatorname{Pr}^{0.148} K_{\lambda}^{0.858} \mathrm{Bo}_{d}{ }^{-1.808} K_{w}{ }^{-3.280}(8)
$$

The dimensionless numbers were calculated from the following equations:

- Nusselt number

$$
N u_{\exp }=\frac{\alpha d_{p}}{\lambda_{l}},
$$

- Reynolds number

$$
R e=\frac{q d_{p} \rho_{l}}{h_{l v} \rho_{v} \mu_{l}},
$$

- Prandtl number

$$
\operatorname{Pr}=\frac{\mu_{l} c_{l}}{\lambda_{l}}
$$

- $\quad$ Bond number

$$
B o_{d}=\left(\frac{d_{p}}{L}\right)^{2},
$$

- $K_{w}$ number

$$
K_{w}=\frac{w_{t u n}}{d_{p}},
$$

- $\quad K_{\lambda}$ number

$$
K_{\lambda}=\frac{\lambda_{C u}}{\lambda_{l}}
$$

The estimated standard deviation of the calculated Nusselt number amounted to 1.5 , and the coefficient of determination, being the measure of accuracy of simple regression matching, was $\mathrm{R}^{2}=0.8343$. Relative errors 
were 0.2 . The correlation was found for 98 observations conducted for water, ethanol, FC-72 and Novec 649. The Nusselt number calculated on the basis of experimental data, $N u_{\text {exp }}$, was compared with theoretical values, $N u_{\text {theor }}$ (figure 4). The correlation was presented with $\pm 40 \%$ tolerance.

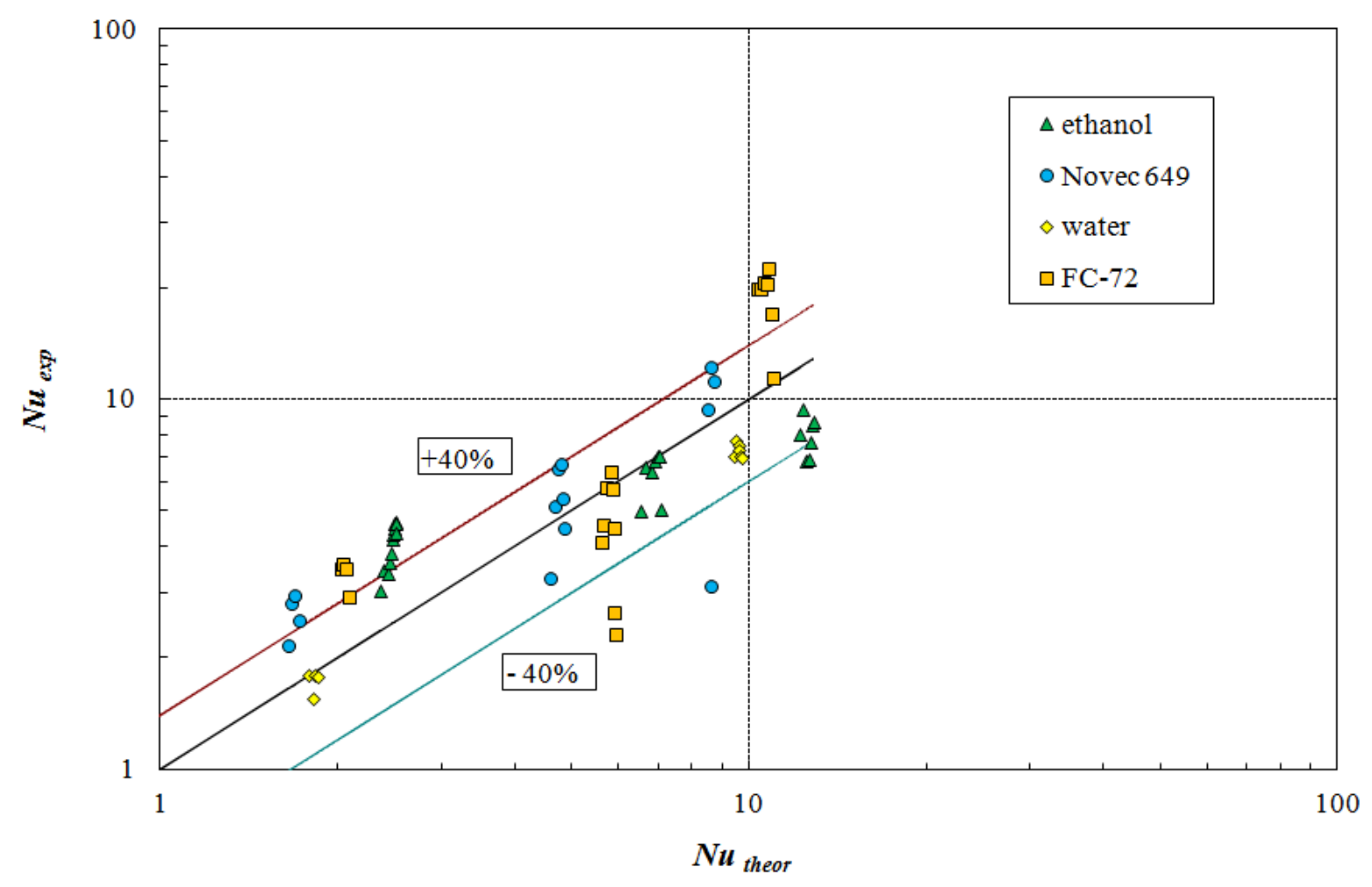

Figure 4. Correlation for pool boiling of water, ethanol FC-72 and Novec 649 for mini-fins with perforated foil.

\section{Conclusions}

It is necessary to match the geometrical dimensions of the tunnels and the diameters of the pores with the characteristic capillary dimension to obtain the highest possible increase in the pool boiling heat transfer coefficient value on the MFP surfaces.

From the present study the following conclusions can be drawn:

- For boiling FC-72 and ethanol, the heat transfer coefficients obtained from the MFP surfaces were more than 5 times higher than those for the smooth surface.

- For boiling water, the heat transfer coefficients obtained from the MFP surfaces were almost 2 times higher than those for the smooth surface and for boiling Novec $649-2.5$ times higher than those for the smooth surface.

- Low values of $B o_{d}^{0.5}\left(w_{\text {tun }} / h_{\mathrm{f}}\right)$ should be used for the best heat transfer coefficient enhancement for the boiling liquids with high value of the capillary length (water, ethanol).
- Using a regression analysis with reference to selected physical properties and several characteristic dimensions, it was possible to develop correlations to calculate the heat transfer coefficient with $\pm 40 \%$ tolerance.

\section{References}

1. Y.-Y. Li, Y.-J. Chen, Z.-H. Liu, Int. J. Heat Mass Transfer 77, 809-817 (2014)

2. A. H. Tarrad, JJMIE vol. 5, nr 2, 139-144, (2011)

3. A. S. Moita, E. Teodori, A. L. N. Moreira, Int. J. Heat Fluid Flow 52, 50-63, (2015)

4. E. Rooyen, J.R. Thome, Int. J. Refrigeration 36, 447455 (2013)

5. E. Nadstawna, R. Pastuszko, MATEC Web of Conferences 18, 01008 (2014)

6. R. Pastuszko, EPJ Web of Conferences, 67, 02090 (2014)

7. R. Pastuszko, T. Wójcik, Exp. Therm. Fluid Sci. 63, 34-44 (2015) 